\title{
ANALISIS KEKUATAN TARIK KAMPUH V DAN KAMPUH I SAMBUNGAN LAS BAJA KARBON RENDAH YANG TERDAPAT PADA BESI IWF 400
}

\author{
Irzal, Walid Orjela dan Syahrul \\ Jurusan Teknik Mesin, Fakultas Teknik, Universitas Negeri Padang \\ Kampus Air Tawar, Padang 25131, Indonesia \\ Corresponding Author: irzalk3@ft.unp.ac.id
}

\begin{abstract}
Abstrak
Penyambungan logam dengan teknik sambungan las masih banyak digunakan diproyek pengelasan salah satunya dengan menggunakan tipe sambungan I. Untuk mendapatkan suatu hasil pengelasan sambungan yang baik ditentukan beberapa faktor, diantaranya sifat mampu las material, jenis sambungan, posisi pengelasan dan elektroda yang digunakan. Diproyek pengelasan masih ada juru las yang hanya menggunakan kampuh I dalam pengelasan menyambung besi IWF 400 padahal ketebalan materialnya $13 \mathrm{~mm}$. Penelitian ini bertujuan untuk mengetahui pengaruh penggunaan kampuh terhadap kekuatan sambungan las dengan menggunakan Elektroda LB 52U $\varnothing 2,6 \mathrm{~mm}$ dan elektroda RD $7018 \varnothing 3,2 \mathrm{~mm}$ dengan Arus AC. Pada penelitian ini menggunakan metode eksperimen dimulai dengan membuat spesimen. Dengan pengambilan 7 spesimen yang terdiri dari 3 spesimen dengan perlakuan pengelasan dengan menggunakan kampuh $\mathrm{V}, 3$ spesimen dengan perlakuan pengelasan dengan menggunakan kampuh I dan 1 spesimen IWF 400 tanpa perlakukan pengelasan. Dari hasil penelitian yang dilakukan pada spesimen dengan membuat dan menguji spesimen dengan mesin uji tarik Hydraullic Universal Material Testing Machine maka didapatkan pada spesimen tanpa pengelasan nilai rata-rata Tegangan Maksimum ( $\sigma \max )$ 41,28 $\mathrm{kg} / \mathrm{mm}^{2}$. Pada spesimen las dengan sambungan kampuh V nilai rata-rata Tegangan Maksimum ( $\sigma$ max) 39,82 $\mathrm{kgf} / \mathrm{mm}^{2}$. Pada spesimen las dengan sambungan kampuh I tegangan maksimum ( $\sigma \max ) 38,32 \mathrm{kgf} / \mathrm{mm}^{2}$. Hasil penelitian ini menunjukkan hasil pengelasan besi IWF 400 menggunakan kampuh V lebih besar nilai tegangannya 39,82 $\mathrm{kgf} / \mathrm{mm}^{2}$. Dari nilai tegangan maksimum yang didapat dari penelitian ini disarankan sebaiknya dalam pengelasan besi IWF 400 menggunakan kampuh V.
\end{abstract}

Kata Kunci: Kekuatan Tarik, Kampuh V, Kampuh I, Sambungan Las, Besi IWF 400.

\begin{abstract}
Metal connection with welded connection technique is still widely used in welding project one of them by using connection type I. To get a good welding result is determined several factors, including the properties of material welding, connection type, welding position and electrode used. In welding project there is still a welder that only uses I in the weld IWF 400 connecting iron while the thickness of the material $13 \mathrm{~mm}$. This study aims to determine the effect of the use of campuh against the strength of weld joint connection using LB $52 \mathrm{U} \varnothing 2.6 \mathrm{~mm}$ Electrode and $R D 7018 \varnothing 3.2 \mathrm{~mm}$ electrode with $A C$ Flow. In this study using experimental method begins with making specimens. With the collection of 7 specimens consisting of 3 specimens with welding treatment using Camp V, 3 specimens with welding treatment using Camp I and I IWF 400 specimens without welding treatment. From the results of research conducted on specimens by making and testing specimens with a tensile test machine Hydraullic Universal Material Testing Machine then obtained on the specimen without welding average value of Maximum (omax) 41,28 kgf/ $\mathrm{mm}^{2}$. In welded specimens with a connection of the $V$ values the average value of the Maximum (omax) $39,82 \mathrm{kgf} / \mathrm{mm}^{2}$. On a welded specimen with a maximum I knot connection (omax) 38,32 kgf/ $\mathrm{mm}^{2}$.The results of this study indicate the results of iron welding IWF 400 using camp V greater value voltage $39.82 \mathrm{kgf} / \mathrm{mm}^{2}$. From the maximum voltage value obtained from this study it is recommended that iron welding IWF 400 uses $V$.
\end{abstract}

Keywords: Tensile Strength, Camp V, Camp I, Welded Connections, IWF 400 Iron. 


\section{A. Pendahuluan}

Perkembangan zaman yang disertai kemajuan ilmu pengetahuan dan teknologi dibidang kontruksi memiliki peranan penting dalam rekayasa dan reparasi logam. Logam yang sering digunakan salah satunya adalah baja. Baja merupakan paduan antara besi $(\mathrm{Fe})$ dan karbon (C) yang merupakan bahan dasar yang sering digunakan untuk berbagai rekayasa teknik. Las SMAW (Shield Metal Arc Welding) atau disebut juga dengan las listrik merupakan salah satu proses pengelasan las busur yang paling sederhana dan banyak di gunakan di dunia Industri. Dalam prakteknya pengelasan dengan las SMAW dapat digunakan untuk pengelasan baja karbon rendah seperti besi IWF 400. Besi IWF 400 merupakan profil baja struktural yang memiliki ukuran Tinggi $(\mathrm{H})=400 \mathrm{~mm}$, Lebar $(B)=200 \mathrm{~mm}$, Tebal Badan $t_{1}=8 \mathrm{~mm}$, dengan materialnya yang berbentuk penampang seperti huruf $\mathrm{H}$ biasa digunakan untuk konstruksi baja. Selain besi IWF 400 dikenal juga profil baja struktural yang lain seperti profil I, U, C, dan HBeam. Teknik penyambungan logam dengan las masih banyak digunakan diproyek pengelasan.Untuk mendapatkan suatu hasil pengelasan sambungan yang baik ditentukan beberapa faktor, diantaranya sifat mampu las material, jenis sambungan, posisi pengelasan dan elektroda yang digunakan. Pemilihan jenis sambungan las bisa mempengaruhi hasil kekuatan lasnya karena bisa berakibat fatal bagi konstruksi itu sendiri jika kekuatan sambungan lasnya tidak kuat jika digunakan dalam suatu konstruksi. Menurut Harsono Wiryosumarto (2008:212) menyatakan "pada umumnya untuk pengelasan pelat dengan tebal sampai dengan $6 \mathrm{~mm}$ digunakan alur persegi, untuk pelat dengan pelat 6 $\mathrm{mm}$ sampai $20 \mathrm{~mm}$ digunakan alur $\mathrm{V}$ tunggal dan yang lebih tebal lagi dengan alur $\mathrm{V}$ ganda atau $\mathrm{U}$ tunggal atau ganda". Tetapi kenyataan dilapangan masih ada juru las diproyek yang tidak menggunakan kampuh $\mathrm{V}$ dalam penyambungan besi IWF 400 yang ketebalan materialnya mencapai $13 \mathrm{~mm}$ dan hanya menggunakan kampuh I. Maka perlu adanya pengujian tarik untuk mengetahui seberapa besar kekuatan hasil sambungan pengelasan dengan kampuh $\mathrm{V}$ dan kampuh I. Berdasarkan latar belakang masalah di atas, penulis tertarik melakukan penelitian dengan judul "Analisis Kekuatan Tarik Kampuh V dan Kampuh I Sambungan Las Baja Karbon Rendah yang Terdapat pada Besi IWF 400“.

\section{B. Metode Penelitian}

Penelitian ini merupakan penelitian eksperimen yang menganalisis kekuatan tarik hasil pengelasan sambungan nbaja karbon rendah besi IWF 400 menggunakan kampuh V dan kampuh I. Menurut Sugiyono (2008:72) "Metode penelitian eksperimen merupakan metode penelitian yang digunakan untuk mencari pengaruh perlakuan tertentu terhadap yang lain dalam kondisi yang terkendalikan". Dimana hasil pengujian diperoleh melalui percobaan langsung terhadap benda uji. Berdasarkan pokok maslah yang di bahas dalam bab sebelumnya, maka data penelitian berupa hasil pengujian kekuatan tarik selanjutnya diamati dan dianalisa untuk mengetahui ada atau tidaknya pengaruh hasil pengelasan dengan kampuh $\mathrm{V}$ dan kampuh I terhadap kekuatan sambungan lasnya dengan las SMAW. Instrumen pengumpulan data pada penelitian ini adalah melalui tabulasi hasil pengujian dengan aspek penelitian yaitu :

1. Menyiapkan tabel-tabel yang dibutuhkan yang sesuai dengan penelitian yang dilakukan.

2. Mengisi tabel-tabel tersebut dengan data hasil pengujian dan menganalisanya.

Tabel 1. Tabulasi Data Pengujian Tarik

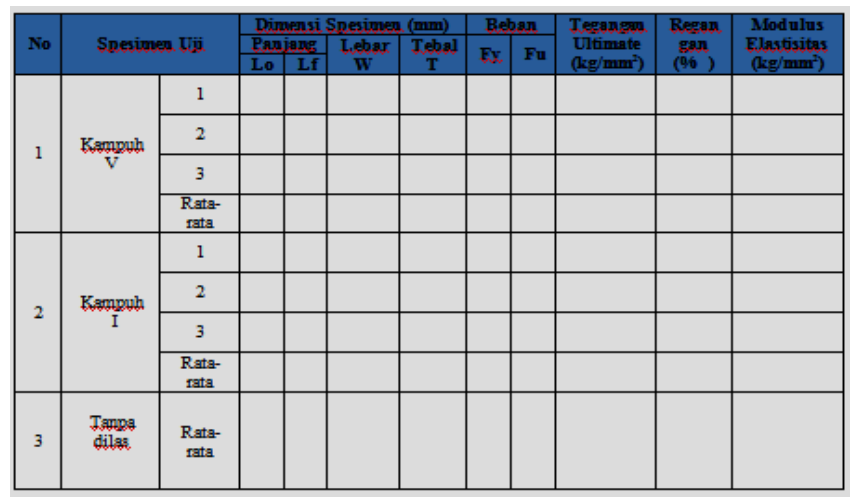

Keterangan:

Ao = Luas Penampang

$>\mathrm{Fy}=$ Beban Luluh

$>\mathrm{Fm}=$ Beban Tarik

$>\sigma \mathrm{u}=$ Tegangan Ultimate

$>\mathcal{E}=$ Regangan

$>\mathrm{E}=$ Modulus Elastisitas

Data yang telah di dapat dari hasil pengujian di susun guna mendapat nilai kekuatan tarik dari masing-masing spesimen. Nilai kekuatan tarik dapat di hitung dengan rumus: 
1. Tegangan $(\sigma)$

$\sigma=\frac{F}{A o}$ Bondan T.Sofyan, 2010:27 (1)

Keterangan :

$\sigma=$ Tegangan $\left(\mathrm{N} / \mathrm{mm}^{2}\right)$

$\mathrm{F}=$ Gaya $(\mathrm{N})$

Ao $=$ Luas penampang spesimen $\left(\mathrm{mm}^{2}\right)$

2. Regangan $(\varepsilon)$

$$
\varepsilon=\frac{L i-L o}{L o} \times 100 \%
$$

Keterangan :

$\varepsilon=$ Regangan

$\mathrm{Li}=$ Panjang spesimen setelah pengujian $(\mathrm{mm})$

Lo $=$ Panjang spesimen sebelum pengujian $(\mathrm{mm})$

3. Modulus Elastis (E)

$$
\mathrm{E}=\frac{\sigma}{\varepsilon}
$$

Keterangan :

$\mathrm{E}=$ Modulus Elastisitas $\left(\mathrm{N} / \mathrm{mm}^{2}\right)$

$\sigma=$ Tegangan tarik $\left(\mathrm{N} / \mathrm{mm}^{2}\right)$

$\varepsilon=$ Regangan $(\%)$

\section{Hasil dan Pembahasan}

\section{Hasil Pengujian Tarik}

Hasil pengujian tarik yang dilaksanakan di laboratorium Kontruksi Jurusan Teknik Sipil Universitas Negeri Padang, maka didapat datadata sebagai berikut:

\begin{tabular}{|c|c|c|c|c|c|c|c|c|c|}
\hline \multirow{3}{*}{ No } & \multirow{3}{*}{\multicolumn{2}{|c|}{$\begin{array}{l}\text { Spesimen Uji } \\
\text { Besi IWF } 400\end{array}$}} & \multicolumn{4}{|c|}{ Dimensi Spesimen (mm) } & \multirow{3}{*}{$\begin{array}{c}\text { Luas } \\
\text { Penampan } \\
\text { g } \\
\text { Ao }\left(\mathrm{mm}^{2}\right)\end{array}$} & \multicolumn{2}{|c|}{$\begin{array}{l}\text { Beban } \\
\text { (kN) }\end{array}$} \\
\hline & & & \multicolumn{2}{|c|}{ Panjang } & \multirow{2}{*}{$\frac{\text { Lebar }}{\text { w }}$} & \multirow{2}{*}{$\frac{\text { Tebal }}{\mathrm{T}}$} & & \multirow{2}{*}{ Fy } & \multirow{2}{*}{ Fm } \\
\hline & & & Lo & $\mathbf{L i}$ & & & & & \\
\hline 1 & $\begin{array}{l}\text { Tanpa } \\
\text { dilas }\end{array}$ & $\begin{array}{l}\text { Rata- } \\
\text { rata }\end{array}$ & 100 & 140,1 & 26,2 & 13 & 340,6 & 89 & 138 \\
\hline \multirow{4}{*}{2} & \multirow{4}{*}{$\underset{\mathbf{V}}{\text { Kampuh }}$} & 1 & 100 & 120,5 & 32,4 & 13 & 421,2 & 104 & 160 \\
\hline & & 2 & 100 & 128,2 & 30,2 & 13 & 392,6 & 101 & 157 \\
\hline & & 3 & 100 & 133,9 & 26,7 & 13 & 347,1 & 89 & 137 \\
\hline & & $\begin{array}{l}\text { Rata- } \\
\text { rata }\end{array}$ & & & & & & & \\
\hline \multirow{4}{*}{3} & \multirow{4}{*}{$\underset{\text { I }}{\text { Kampuh }}$} & 1 & 100 & 117,5 & 32,3 & 13 & 419,9 & 99 & $\begin{array}{c}168, \\
5\end{array}$ \\
\hline & & 2 & 100 & 115,6 & 30,1 & 13 & 391,3 & 103 & 128 \\
\hline & & 3 & 100 & 119,2 & 26,5 & 13 & 344,5 & 83 & 138 \\
\hline & & $\begin{array}{l}\text { Rata- } \\
\text { rata }\end{array}$ & & & & & & & \\
\hline
\end{tabular}

Tabel 2. Hasil Pengujian Tarik

Setelah melakukan pengujian tarik, maka dapat dicari dengan rumus:

Kekuatan tarik $=\frac{\text { gaya terbesar }}{\text { luas penampang }}$ atau $\quad \sigma=$

\section{$\frac{F}{A o}$}

Dimana : $\sigma=$ Tegangan tarik dalam $\mathrm{kgf} / \mathrm{mm}^{2}$

$\mathrm{F}$ =Beban maximum pada waktu pengujian dalam $\mathrm{kg}$

Ao = Luas pena mpang dalam $\mathrm{mm}^{2}$

Pada perhitungan kekuatan tarik, pada pengujian ini hanya diambil nilai rata-rata dari hasil data spesimen uji tarik yang menggunakan kampuh $\mathrm{V}$, kampuh I dan tanpa dilas.

\section{a. Spesimen Kontrol (Tanpa Pengelasan)}

Spesimen 1:

$\sigma=\frac{F}{A o}=\frac{138 \mathrm{kN}}{340,6 \mathrm{~mm}^{2}}=0,405 \mathrm{~N} / \mathrm{mm}^{2}$

$=41,28 \mathrm{kgf} / \mathrm{mm}^{2}$

$\varepsilon=\frac{\Delta L}{L 0} \times 100 \%=\frac{140,1 \mathrm{~mm}-100 \mathrm{~mm}}{100 \mathrm{~mm}} \times 100 \%$

$=40,1 \%=0,401$

$\mathrm{E}=\frac{\sigma}{\varepsilon}=\frac{41,28 \mathrm{kgf} / \mathrm{mm}}{0,401}=102,94 \mathrm{~kg} / \mathrm{mm}^{2}$

\section{b. Spesimen Dengan Kampuh V}

Spesimen 1:

$\sigma=\frac{F}{A o}=\frac{160 k N}{421,2 \mathrm{~mm}^{2}}=0,379 \mathrm{~N} / \mathrm{mm}^{2}$

$=38,63 \mathrm{kgf} / \mathrm{mm}^{2}$

$\varepsilon=\frac{\Delta L}{L 0} \times 100 \%=\frac{120,5 \mathrm{~mm}-100 \mathrm{~mm}}{100 \mathrm{~mm}} \times 100 \%$

$=20,5 \%=0,205$

$\mathrm{E}=\frac{\sigma}{\varepsilon}=\frac{38,63 \mathrm{kgf} / \mathrm{mm}}{0,205}=188,44 \mathrm{~kg} / \mathrm{mm}^{2}$

Spesimen 2:

$\sigma=\frac{F}{A o}=\frac{157 \mathrm{kN}}{392,6 \mathrm{~mm}^{2}}=0,399 \mathrm{~N} / \mathrm{mm}^{2}$

$=40,67 \mathrm{kgf} / \mathrm{mm}^{2}$

$\varepsilon=\frac{\Delta L}{L 0} \times 100 \%=\frac{128,2 \mathrm{~mm}-100 \mathrm{~mm}}{100 \mathrm{~mm}} \times 100 \%$

$=28,2 \%=0,282$

$\mathrm{E}=\frac{\sigma}{\varepsilon}=\frac{40,67 \mathrm{kgf} / \mathrm{mm}}{0,282}=144,22 \mathrm{~kg} / \mathrm{mm}^{2}$ 
Spesimen 3:

$\sigma=\frac{F}{A o}=\frac{137 \mathrm{kN}}{347,1 \mathrm{~mm}^{2}}=0,394 \mathrm{~N} / \mathrm{mm}^{2}$

$=40,16 \mathrm{kgf} / \mathrm{mm}^{2}$

$\varepsilon=\frac{\Delta L}{L 0} \times 100 \%=\frac{133,9 \mathrm{~mm}-100 \mathrm{~mm}}{100 \mathrm{~mm}} \times 100 \%$

$=33,9 \%=0,339$

$\mathrm{E}=\frac{\sigma}{\varepsilon}=\frac{40,16 \mathrm{kgf} / \mathrm{mm}}{0,339}=118,46 \mathrm{~kg} / \mathrm{mm}^{2}$

\section{c. Spesimen Dengan Kampuh I}

Spesimen 1:

\begin{tabular}{|c|c|c|c|c|}
\hline \multirow{2}{*}{$\begin{array}{c}\text { Variasi } \\
\text { Kampuh }\end{array}$} & \multicolumn{4}{|c|}{ Spesimeno $\left(\mathrm{kgf}^{\mathrm{m}} \mathrm{mm}^{2}\right)$} \\
\cline { 2 - 5 } & $\mathbf{1}$ & $\mathbf{2}$ & $\mathbf{3}$ & $\begin{array}{c}\text { Rata- } \\
\text { rata }\end{array}$ \\
\hline Tanpa Dilas & 41,28 & - & - & $\mathbf{4 1 , 2 8}$ \\
\hline Kampuh V & 38,63 & 40,67 & 40,16 & $\mathbf{3 9 , 8 2}$ \\
\hline Kampuh I & 40,87 & 33,33 & 40,77 & $\mathbf{3 8 , 3 2}$ \\
\hline
\end{tabular}

$\sigma=\frac{F}{A o}=\frac{168,5 \mathrm{kN}}{419,9 \mathrm{~mm}^{2}}=0,401 \mathrm{~N} / \mathrm{mm}^{2}$

$=40,87 \mathrm{~kg} / \mathrm{mm}^{2}$

$\varepsilon=\frac{\Delta L}{L 0} \times 100 \%=\frac{117,5 \mathrm{~mm}-100 \mathrm{~mm}}{100 \mathrm{~mm}} \times 100 \%$

$=17,5 \%=0,175$

$\mathrm{E}=\frac{\sigma}{\varepsilon}=\frac{40,87 \mathrm{kgf} / \mathrm{mm}}{0,175}=233,54 \mathrm{~kg} / \mathrm{mm}^{2}$

Spesimen 2:

$\sigma=\frac{F}{A o}=\frac{128 \mathrm{kN}}{391,3 \mathrm{~mm}^{2}}=0,327 \mathrm{~N} / \mathrm{mm}^{2}$

$=33,33 \mathrm{kgf} / \mathrm{mm}^{2}$

$\varepsilon=\frac{\Delta L}{L 0} \times 100 \%=\frac{115,6 \mathrm{~mm}-100 \mathrm{~mm}}{100 \mathrm{~mm}} \times 100 \%$

$=15,6 \%=0,156$

$\mathrm{E}=\frac{\sigma}{\varepsilon}=\frac{33,33 \mathrm{kgf} / \mathrm{mm}}{0,156}=213,65 \mathrm{~kg} / \mathrm{mm}^{2}$

Spesimen 3:

$$
\begin{aligned}
& \sigma=\frac{F}{A o}=\frac{138 \mathrm{kN}}{344,5 \mathrm{~mm}^{2}}=0,400 \mathrm{~N} / \mathrm{mm}^{2} \\
& =40,77 \mathrm{kgf} / \mathrm{mm}^{2} \\
& \varepsilon=\frac{\Delta L}{L 0} \times 100 \%=\frac{119,2 \mathrm{~mm}-100 \mathrm{~mm}}{100 \mathrm{~mm}} \times 100 \% \\
& =19,2 \%=0,192 \\
& \mathrm{E}=\frac{\sigma}{\varepsilon}=\frac{40,77 \mathrm{kgf} / \mathrm{mm}}{0,192}=212,34 \mathrm{~kg} / \mathrm{mm}^{2}
\end{aligned}
$$

Tabel 3. Hasil Rata-Rata Kekuatan Tarik

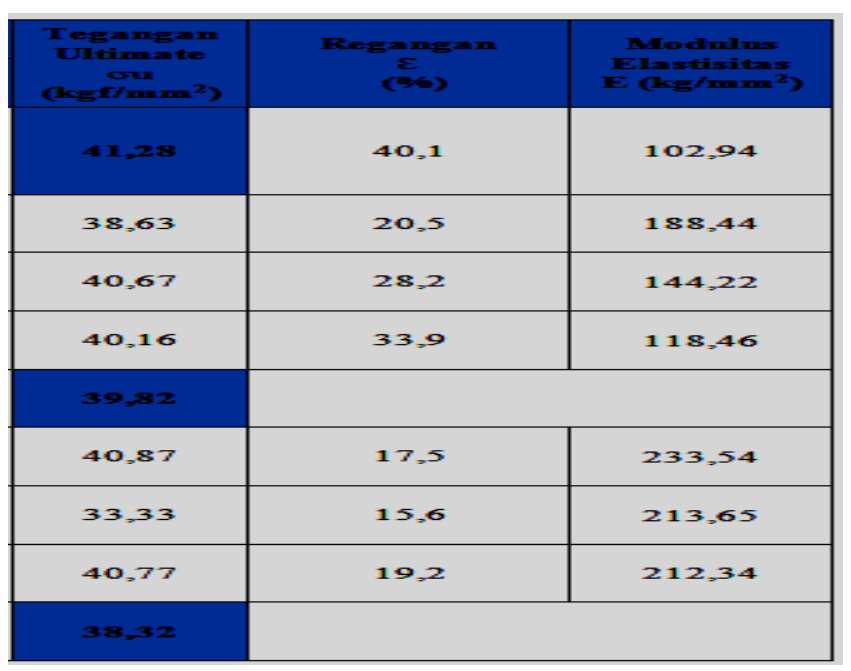

\section{Pembahasan}

Bahan yang digunakan dalam penelitian ini adalah baja karbon rendah yang terdapat pada besi IWF 400. Spesimen yang digunakan dalam penelitian ini ada 7 spesimen spesimen yang terdiri dari 1 spesimen kontrol, 3 spesimen pengelasan dengan kampuh $\mathrm{V}, \quad 3$ spesimen pengelasan dengan kampuh I . Pada semua spesimen tersebut dilakukan pengujian tarik yang bertujuan untuk mengetahui kekuatan tarik dari masing-masing spesimen tersebut.

a. Spesimen Tanpa Dilas

Spesimen ini tidak mendapatkan proses pengelasan, hal ini bertujuan untuk menjadi kontrol pada spesimen yang mendapatkan perlakuan pengelasan. Dari hasil pengujian tarik terhadap spesimen ini didapat nilai kekuatan tarik spesimen kontrol sebesar 41,28 $\mathrm{kgf} / \mathrm{mm}^{2}$. Sehingga kekuatan tarik rata-rata nya yang didapat sebesar $\mathbf{4 1 , 2 8} \mathbf{~ k g f} / \mathbf{m m}^{2}$. Nilai tersebut merupakan nilai kekuatan tarik standar untuk baja karbon rendah dan merupakan nilai kekuatan tarik standar. Hal tersebut terjadi karena spesimen tidak mendapatkan proses pengelasan sehingga tidak terjadi perubahan struktur pada spesimen tersebut. Spesimen ini hanya untuk melihat kekuatan tarik aslinya dan juga sebagai pembanding ukuran kekuatan spesimen yang lain setelah dilakukan pengujian tarik apakah kekuatan tariknya lebih rendah atau lebih tinggi dibanding beberapa spesimen yang dilakukan pengelasan. 


\section{b. Spesimen Dengan Kampuh V}

Pada spesimen ini dilakukan proses pengelasan dan kemudian hasil pengelasan di bagi menjadi 3 bagian untuk dilakukan pengujian. Dari hasil pengujian tarik terhadap spesimen ini didapat nilai kekuatan tarik spesimen 1 sebesar 38,63 $\mathrm{kgf} / \mathrm{mm}^{2}$, kekuatan tarik spesimen 2 sebesar 40,67 $\mathrm{kgf} / \mathrm{mm}^{2}$, spesimen 3 sebesar $40,16 \mathrm{kgf} / \mathrm{mm}^{2}$, sehingga kekuatan tarik rata-rata nya didapat sebesar 39,82 kgf/ $/ \mathbf{m m}^{2}$. Nilai tersebut merupakan nilai kekuatan tarik yang paling bagus bila dibandingkan dengan spesimen yang menggunakan kampuh I setelah mendapatkan perlakuan pengelasan.

\section{c. Spesimen Dengan Kampuh I}

Pada spesimen ini dilakukan proses pengelasan dan kemudian hasil pengelasan di bagi menjadi 3 bagian untuk dilakukan pengujian. Dari hasil pengujian tarik terhadap spesimen ini didapat nilai kekuatan tarik spesimen 1 sebesar 40,87 $\mathrm{kgf} / \mathrm{mm}^{2}$, kekuatan tarik spesimen 2 sebesar 33,33 $\mathrm{kgf} / \mathrm{mm}^{2}$, spesimen 3 sebesar 40,77 $\mathrm{kgf} / \mathrm{mm}^{2}$, sehingga kekuatan tarik rata-rata nya didapat sebesar 38,32 $\mathbf{~ k g f} / \mathbf{m m}^{2}$. Nilai tersebut merupakan nilai kekuatan tarik yang terendah bila dibandingkan dengan spesimen yang menggunakan kampuh $\mathrm{V}$ dan spesimen. Hal ini disebabkan karena tebal material besi IWF 400 tidak disesuaikan dengan kampuh yang sebaiknya digunakan. Untuk pengelasan yang menggunakan kampuh $\mathrm{V}$ kekuatan tarik baja karbon rendah yang terdapat pada besi IWF 400 yang di las menggunakan elektroda LB 52U diameter 2,6 mm untuk penembusan awal dengan arus $70 \mathrm{~A}$ dan dilanjutkan dengan pengisian yang dilakukan dengan elektroda $\mathrm{E} 7018$ diameter 3,2 mm dengan tebal material baja $13 \mathrm{~mm}$ menggunakan arus 110 A pada mesin las AC, memiliki kekuatan tarik yang paling baik jika dibandingkan dengan material besi IWF 400 yang dilas dengan kampuh I. Spesimen yang digunakan dalam penelitian ini berjumlah 7 spesimen yang terdiri dari 1 spesimen kontrol, 3 spesimen pengelasan dengan kampuh V, 3 spesimen pengelasan dengan kampuh I. Pada masing-masing spesimen mengalami lokasi putus yang berbeda-beda antara ketiga jenis spesimen tersebut. Spesimen dilas dengan kampuh V lokasi putus berada dilokasi daerah logam induk, pada spesimen di las dengan kampuh I lokasi putus satu buah spesimen berada pada daerah las dan hanya 1 spesimen tidak semuanya dan spesimen tanpa dilas lokasi putusnya berada diantara tengah spesimen. Hal tersebut menunjukkan bahwa terdapat perbedaan antara spesimen yang dilas dengan kampuh V, kampuh I dan tanpa di las yang menunjukan hasil pengujian tariknya dari lokasi putus spesimen yang terlihat seperti gambar dibawah ini.

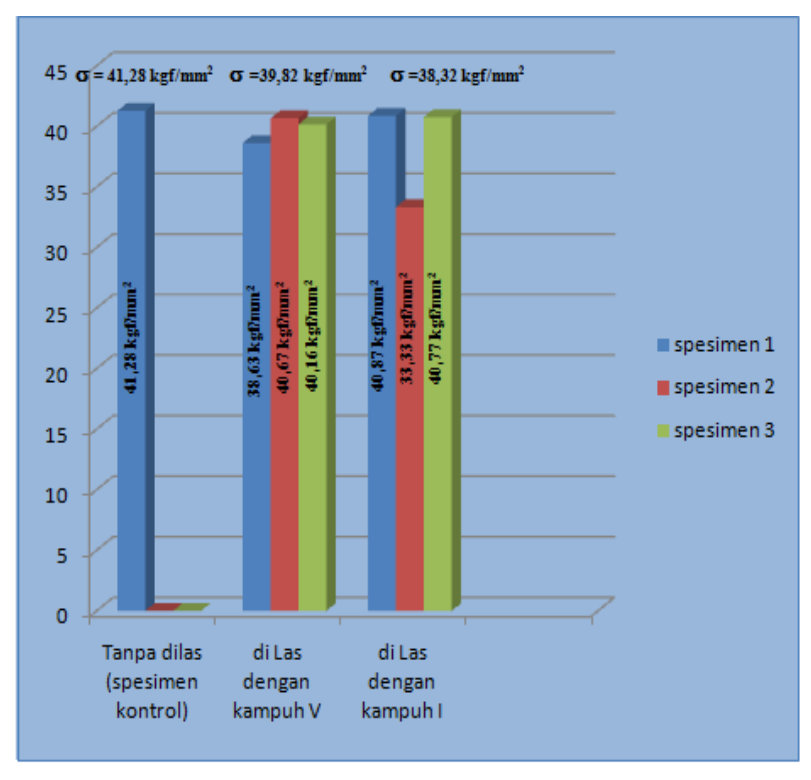

Gambar 1. Grafik Tegangan kampuh V, kampuh I dan Tanpa Dila

\section{Kesimpulan}

Hasil penelitian yang telah dilakukan dapat disimpulkan bahwa:

1. Perbedaan kekuatan sambungan lasnya terlihat pada hasil pengujian spesimen dengan kampuh $\mathrm{V}$ kekuatan tarik rata-ratanya sebesar $\mathbf{3 9 , 8 2}$ kgf/ $\mathbf{~ m m}^{2}$, sedangkan kekuatan tarik spesimen dengan kampuh I kekuatan tarik rata-ratanya sebesar $38,32 \mathrm{kgf} / \mathbf{~ m m}^{2}$.

2. Pada spesimen yang dilas dengan kampuh $\mathrm{V}$ lokasi putus berada di daerah logam induk, pada spesimen las dengan kampuh I lokasi putusnya ada yang berada pada daerah las.

3. Untuk pengelasan sambungan pada besi IWF 400 dengan ketebalan materialnya $13 \mathrm{~mm}$ sebaiknya menggunakan kampuh $\mathrm{V}$ karena hasil pengujian menunjukkan nilai kekuatan tarik rata-ratanya lebih besar kampuh $\mathrm{V}$ dari pada kampuh I.

\section{Referensi}

Bondan T. Sofyan. (2010). Pengantar Material Teknik. Jakarta: Salemba Teknika.

Jasman, J., Irzal, I., Adri, J., \& Pebrian, P. (2018). Effect of Strong Welding Flow on the Violence of Low Carbon Steel Results of 
SMAW Welding with Electrodes 7018. Teknomekanik, 1(1), 24-31. Retrieved from http://teknomekanik.ppj.unp.ac.id/index. php/tekno/article/view/9

Harsono Wiryosumarto, Toshie Okumura. (2008). Teknologi Pengelasan Logam. Jakarta: Pradnya Paramita.

Nabawi, R. A. (2012). Analisis kekuatan Tarik Komposit Polimer Berpenguat Serat Eglass yang Diberi Perlakuan Alkali (NAOH). Skripsi: Universitas Negeri Padang

Sugiyono. (2008). Metode Penelitian Kuantitatif, Kualitatif dan $R \& D$. Bandung: Alfabeta.

Yondri, S., Nabawi, R. A., \& Islami, S. (2017, October). Utilization of Potential Water Energy in Irrigation Channels for PicoHydro Power Plant. In International Conference of Applied Science on Engineering, Business, Linguistics and Information Technology (pp. 161-163). ICo-ASCNITECH.

Yondri, S., Nabawi, R. A., Sunitra, E., Islami, S., \& Asrul, J. (2017, October). The Machine Punch Mulch: A Pneumatic Pierching and Control With Fuzzy Logic Control. In International Conference of Applied Science on Engineering, Business, Linguistics and Information Technology (pp. 148-152). ICo-ASCNITECH. 